\title{
Histórias afro-atlânticas
}

Ricardo Obtake I

$\mathrm{O}_{\mathrm{d}}^{\mathrm{s}}$ 130 anos que separam a assinatura da Lei Áurea, que determinava a abolição da escravatura, dos dias de hoje não foram suficientes para extinguir as consequências de um dos mais violentos períodos da história do Brasil, iniciados quase três séculos atrás, ainda manifesto tanto por meio de preconceitos e maus-tratos, que ainda ocorrem de forma ilegal, como também a partir da violência oficial, encarceramento em massa e da falta de oportunidades iguais para a população negra, nas plantações e nos pesados encargos urbanos e domésticos.

Esse violento processo não se restringiu ao Brasil: praticamente todos os países da América receberam negros oriundos da diáspora africana para trabalharem como mão de obra escrava, quase sempre em condição degradante. Para além de produzir cicatrizes e questões que persistem até hoje, esse processo teve como palco o Oceano Atlântico, produziu também uma série de imagens, documentos, textos, fotografias e outras obras de arte que se debruçavam sobre o tema. $\mathrm{O}$ assunto, em função das consequências existentes, mostra até hoje inquietações em artistas contemporâneos, principalmente negros, que por vezes resgatam o tema e trabalham em cima da própria iconografia da época, criando leituras atuais sobre fatos formadores.

Duas instituições artísticas brasileiras, o Museu de Arte de São Paulo (Masp) e o Instituto Tomie Ohtake, tomaram a decisão de realizar uma extensa exposição com esse material. $O$ período da mostra foi de 28 de junho a 21 de outubro de 2018, com um acervo cabendo
$60 \%$ ao Masp e $40 \%$, ao Instituto Tomie Ohtake, com 504 obras de 215 artistas, de 54 instituições de 13 países, e 62 galerias e coleções particulares do mundo, divididas em oito capítulos: 1 Mapas e margens; 2 Emancipações; 3 Cotidianos; 4 Ritos e ritmos; 5 Rotas e transes: Áfricas, Jamaica, Bahia; 6 Retratos; 7 Modernismos afro-atlânticos; 8 Resistências e ativismos. A curadoria coube a Adriano Pedrosa, Ayrson Heráclito, Hélio Menezes, Lilia Moritz Schwarcz e Tomás Toledo, e a organização editorial, a Adriano Pedrosa e Tomás Toledo.

Simultaneamente à exposição, foi editada uma publicação $(27,5 \times 20,5 \mathrm{~cm}$, 416 páginas) com a reprodução de todas as obras e com textos gerais e específicos de cada capítulo da mostra, escritos pelos vários curadores, com expressiva concepção visual e preciosa qualidade de impressão gráfica, necessárias à compreensão cromática, textural, e do uso do material - tinta a óleo sobre tela ou sobre papel, fotografia impressa em platina ou em prata, textura de esculturas de madeira, peças em metal.

A moderna concepção do livro de arte é muito diferente do livro de texto. Este tem em todas as páginas duplas a mesma diagramação, e mesmo quando haja ilustração essas ficam dentro da mancha de texto, ao contrário do livro contemporâneo de arte cuja liberdade de diagramação faz parte do entendimento da própria arte.

É essa característica que difere a velha gráfica da que domina a produção de pouco mais de meio século e que se desenvolve numa extraordinária veloci- 


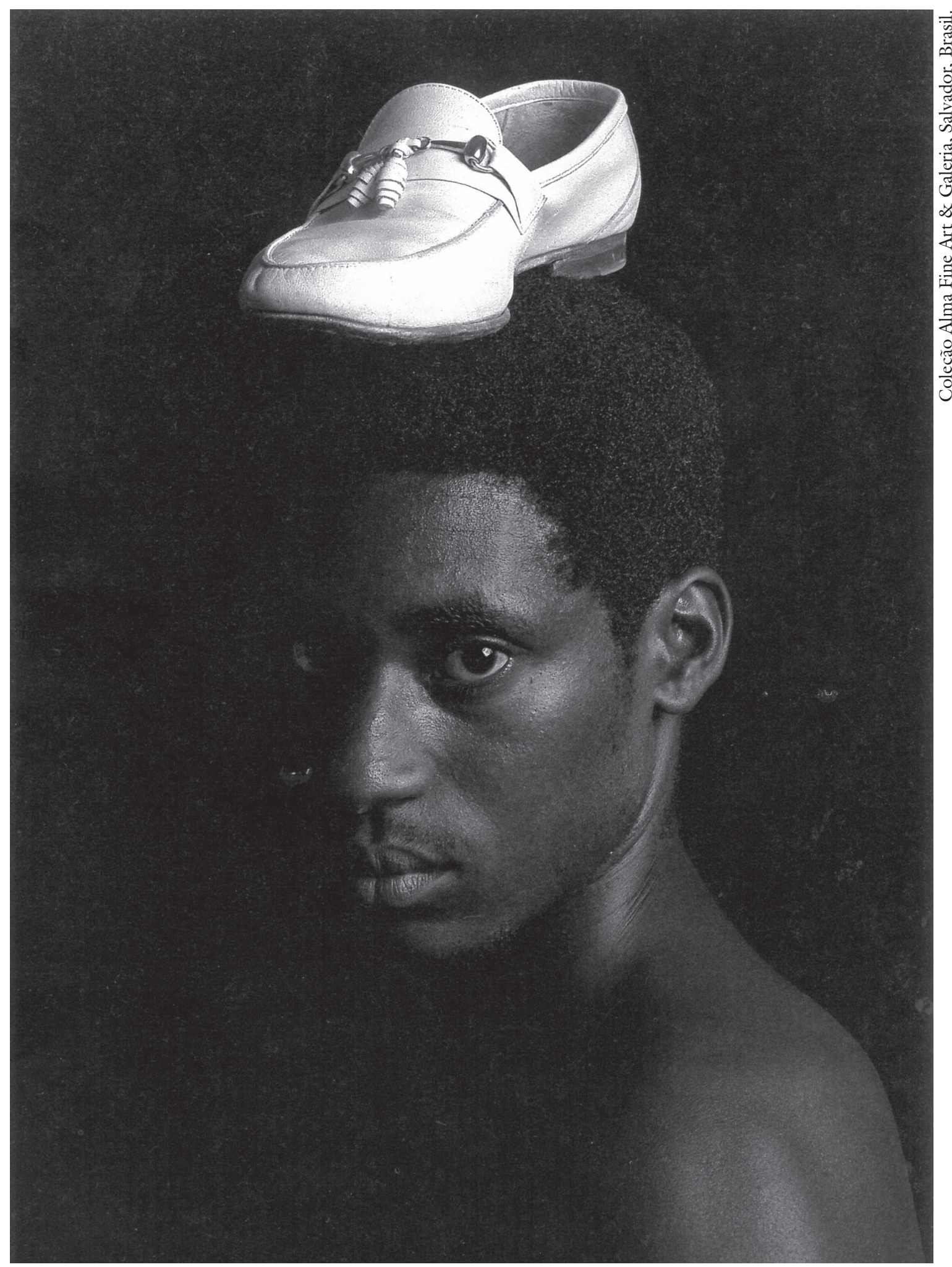

Bauer Sá. Salvador, Brasil, 1950- vive em Salvador. Sapato branco, sem data. 
dade exclamações na admiração de belos exemplares e com uma tecnologia muito aperfeiçoada do sistema industrial de impressão que significa a máquina impressora, o processo de pré-impressão, o papel e a tinta, sem contar a reprodução fotográfica incluindo sofisticada iluminação de cada obra, o acabamento do exemplar etc.

A localização do Oceano Atlântico em relação à África e às costas americanas mostra a grande extensão da distribuição dos negros vindos de um continente para outro, os tamanhos das embarcações que trouxeram a mão de obra, desde os primeiros escravizados, depois transportados, são centrais nessa exposição com obras de artistas fundamentais como Portinari, Mendive, Gilberto de la Nuez, e os atuais Emanoel Araujo, Paulo Nazareth, Jaime Lauriano, Sidney Amaral, Rosana Paulino e Faith Ringgold, entre muitos outros.

O dia a dia da escravidão sempre foi muito violento, apesar de haver imagens em que uma suposta suavidade e vida confortável aparece em desenhos e pinturas, mas também cenas em que os negros escravizados apareciam muito violentados e açoitados, chegando até a haver censura por parte do Instituto Histórico e Geográfico Brasileiro, pois a elite brasileira pretendia divulgar um processo menos violento.

O cotidiano é bastante registrado, tanto nas zonas rurais como nas vilas, desde as conhecidas imagens dos artistas do grupo de Mauricio de Nassau, principalmente Frans Post, como de outros europeus, o francês Jean Chauffrey, o jamaicano Isaac Mendes Belisario, o inglês Charles Landseer, o espanhol Victor Patricio Landaluze, o francês que viveu no Brasil Félix Émile Taunay, o britâni- co Henry Chamberlain, que viveu entre o século XVII e o século XIX nas Américas; depois, temos norte-americanos, centro-americanos e brasileiros já do século XX e num estilo que se aproxima da moderna pintura.

A exposição buscou justamente mostrar como o Atlântico foi palco de todo esse processo, iniciado no século XV, e que, de alguma maneira, persiste até os dias de hoje. Essa dimensão náutica e geográfica da exposição fica muito clara em alguns núcleos: tanto "Mapas e Margens", presente no Masp e que apresenta algumas dessas cartografias, como em "Emancipações", presente no Instituto Tomie Ohtake e que traz alguns trabalhos que discutem a representação do navio negreiro, desde em artistas viajantes estrangeiros, como Rugendas, até artistas contemporâneos brasileiros, como Paulo Nazareth.

A maneira suavizada e romantizada de se representar a escravidão, dentro e fora do Brasil, também é discutida pela mostra, pois essas imagens trazem muitas vezes cenas de violência muito clara. Novamente, releituras feitas por artistas negros são parte importante. Nomes como Jaime Lauriano, Rosana Paulino e Sidney Amaral foram fundamentais nessa empreitada. Tais releituras aparecem lado a lado de aquarelas e telas de nomes como Debret, Rugendas, Briggs e Pedro Américo.

Finalmente, inúmeras imagens de resistências e ativismos negros, desde a época colonial até os dias de hoje, integram salas no Instituto Tomie Ohtake e do Masp. Objetos rituais, pinturas, fotografias e vídeos apresentam algumas dessas formas de se resistir e fazer política no mundo afro-atlântico, além de trazer vários pontos de diálogo e ele- 
mentos iconográficos em comum entre os trabalhos.

Simultaneamente a essa publicação ("Catálogo") foi editado um livro ("Antologia") contendo textos nos quais a curadoria se baseou para a realização da exposição $(24,5 \times 17,7$ cm, 624 páginas $)$.

Referências

PEDROSA, P.; HERÁCLITO, A.; MENEZES, H.; SCHWARCZ, L. M.; TOLEDO, T. (Curadoria e textos). Histoórias Afro-Atlânticas. Volume 1. Catálogo. São Paulo, Instituto Tomie Ohtake; Masp, 2018 416p. Organização editorial Adriano Pedrosa e Tomás Toledo.

PEDROSA, A.; CARNEIRO, A.; MESQUITA, A. Histórias Afro-Atlânticas. Volume 2. Antologia. São Paulo, Instituto Tomie Ohtake; Masp, 2018. 624p. Com a colaboração de Artur Santoro, Hélio Menezes, Lilia Moritz Schwarcz, Tomás Toledo.

Ricardo Obtake dirige o Instituto Tomie Ohtake desde sua criação, em 2001. Foi secretário de Estado da Cultura de São Paulo, dirigiu o Centro Cultural São Paulo, o Museu da Imagem e do Som e a Cinemateca Brasileira. Formou-se em arquitetura pela Faculdade de Arquitetura da Universidade de São Paulo. Foi membro do Conselho Deliberativo do Instituto de Estudos Avançados da USP entre 2015 e 2016 e titular da Cátedra Olavo Setúbal de Arte, Cultura e Ciência do IEA-USP. @ - ricardo.ohtake@institutotomieohtake.org.br https://orcid.org/0000-0002-7897-2796

Recebido em 22.10.2018 e aceito em 11.11 .2018 .

I Instituto Tomie Ohtake, São Paulo, São Paulo, Brasil. 